\title{
BASIDIOMICETOS DA CIDADE DE CASCAVEL - OESTE DO PARANÁ - E SUAS APLICAÇÕES EM BIOTECNOLOGIA
}

\author{
Basidiomycetes from Cascavel City - Western Parana - and their \\ applications in biotechnology
}

\author{
Ingrids Mathias Vieira ${ }^{1}$ \\ Marcelo Henrique da Rocha ${ }^{2}$ \\ Edison BarbosadaCunha ${ }^{3}$ \\ Marina Kimiko Kadowaki ${ }^{4}$ \\ ClariceAokiOsaku ${ }^{4,5}$
}

\section{Resumo}

Foram examinadas e identificadas 18 amostras ( 8 gêneros e 3 famílias) de Basidiomycetes macroscópicos coletadas no período de novembro de 2005 a julho de 2006 na cidade de Cascavel/PR/BR. As espécies identificadas foram: Schizopora carneo-lutea, Poria lenis, Pycnoporus sanguineus, Trametes villosa, Schizophyllum commune, Ganoderma applanatum, Ganoderma resinaceum, Ganoderma australe, Coriolopsis polyzona, Phellinus gilvus. O gênero melhor representado foi Ganoderma, com três táxons distintos e as espécies mais freqüentes foram Trametes villosa e Coriolopsis polyzona. Foi elaborada uma chave de identificação para os táxons encontrados.

Palavras-chave: Polyporaceae; Basidiomicetos; Lignocelulíticos.

\footnotetext{
Aluna do Curso de Especialização em Biotecnologia-UNIOESTE/CASCAVEl. e-mail: ingrids_mv@yahoocom.br Aluno do curso de graduação em Química - UNIOESTE/CASCAVEL. e-mail: marcellohenque@hotmail.com Docente do Centro de Ciências Médicas e Farmacêuticas - UNIOESTE/CASCAVEL. e-mail: edibacunha@bol.com.br Docente do Centro de Ciências Médicas e Farmacêuticas - UNIOESTE/CASCAVEL. e-mail: marinakk@unioeste.br

Doutora, autora para correspondência: Rua Universitária, 2069. CEP 85819-110. Cascavel, PR. Universidade Estadual do Oeste do Paraná. e-mail:cla_osaku@yahoo.com.br
} 


\section{Abstract}

Eighteen samples of macroscopic Basidiomycetes were examined and identified ( 8 genera and 3 families) colleted during November from 2005 to July 2006 in the city of Cascavel/PR/BR. The identified species were: Schizopora carneo-lutea, Poria lenis, Pycnoporus sanguineus, Trametes villosa, Schizophyllum commune, Ganoderma applanatum, Ganoderma resinaceum, Ganoderma australe, Coriolopsis polyzona, Phellinus gilvus. The most representative genus was Ganoderma, with 03 distinct taxons and the most frequent species was Trametes villosa and Coriolopsis polyzona. A key of identification was elaborated for the taxons.

Keywords: Polyporaceae; Basidiomycetes; Lignicolous.

\section{Introdução}

Os fungos poliporáceos, pertencentes ao Filo Basidiomycota são conhecidos popularmente como orelhas de pau. Neste Filo, está reunido o que há de mais derivado dentre os organismos do Reino Fungi e são denominados fungos verdadeiros. As características fisiológicas que padronizam o filo se detêm a uma faixa de temperatura de crescimento entre $20-35^{\circ} \mathrm{C}$, faixa de $\mathrm{pH}$ de crescimento entre 2,0 - 8,5 e pH ótimo: 4,5 $-5,5$. A característica que fundamenta essas espécies é a formação de estruturas denominadas basídios, células em forma de clava e separadas do restante do micélio por septos e onde conseqüentemente ocorre a cariogamia e a meiose, originando os esporos ou também denominados Basidiósporos, que se localizam diretamente na parede dos basídios ou inseridos neles por meio dos esterigmas $(1,2,3)$.

Dentre as espécies da família Polyporaceae é possível encontrar fungos que apresentam tubos ou poros. Frente a isso, é importante ressaltar a diferença entre o termo poliporáceo, que engloba as espécies da família Polyporaceae e que possuem superfície himenial diversificada, variando entre hidnóide a lamelar e poróide, e a expressão poliporóide, que caracteriza as espécies que apresentam a superfície himenial poróide independente da família a qual pertencem (3).

A maioria das espécies forma uma estrutura macroscópica, com hifas modificadas que originam pseudotecidos, denominados de basidioma, basidiocarpo ou corpo de frutificação. Os basidiomas, por apresentarem uma variedade de cores e formas, tornam essas espécies extremamente atrativas ao olhar humano. Além disso, desempenham funções específicas e importantes na natureza, como mineralização e a capacidade de degradação da madeira a partir da regulação de seu sistema enzimático (4). Devido a essa característica, os fungos basidiomicetos foram divididos em dois grupos principais: os causadores de podridão branca, que degradam a celulose, hemicelulose e lignina, e os causadores da podridão parda, que degradam apenas celulose e hemicelulose $(3,5,6)$.

Essas capacidades demonstradas pelas espécies de fungos basidiomicetos os tornam importantes na Biotecnologia pela aplicação industrial desse complexo enzimático e pela aplicação no tratamento de efluentes da indústria têxtil e papeleira, bem como efetivar o processo de biorremediação de solos contaminados com resíduos organoclorados para descontaminação ou redução da poluição ambiental. (3).

O presente trabalho busca a identificação das espécies de fungos basidiomicetos da cidade de Cascavel e verificação da possibilidade de possíveis aplicações biotecnológicas.

\section{Materiais e métodos}

As coletas foram realizadas na cidade de Cascavel, localizada a uma latitude $24^{\circ} 57^{\prime} 21^{\prime \prime}$ Sul e a uma longitude $53^{\circ} 27^{\prime} 19^{\prime \prime}$ Oeste. Sua população estimada é de 278.185 habitantes (em 2005), altitude variando em torno dos $780 \mathrm{~m}$ e uma área de 2.091 $\mathrm{km}^{2}$. Possui clima temperado mesotérmico superúmido, com temperatura média anual em torno de $21^{\circ} \mathrm{C}$. A temperatura média do verão é de $28^{\circ} \mathrm{C} \mathrm{e}$, no inverno, oscila entra $13^{\circ} \mathrm{C}$ e $15^{\circ} \mathrm{C}$, com ocorrência de geadas (http://www.cascavel.pr.gov.br/seplan).

Na região Central, foram feitas coletas nas ruas Duque de Caxias, General Osório, São Paulo, Marechal Rondon, da Bandeira; no Lago Municipal de Cascavel, nos bairros na Rua Ieda Baggio Mayer, Coral, Cascavel, Rua Guanabara, Rio Cascavel e na Chácara da Unioeste, coletando-se um total de 30 amostras.

Os espécimes analisados foram obtidos a partir de coletas realizadas no período de agosto do ano de 2005 a março de 2006, abrangendo, dessa forma, duas estações do ano diferentes. A coleta das amostras e sua preservação foram realizadas de acordo com as recomendações técnicas de Fidalgo e Bononi (7). 
O trabalho de identificação das espécies foi realizado a partir da análise das características macro e microscópicas. A análise macroscópica inclui: forma, longevidade e tipo do basidioma, formato e medidas do píleo, características da superfície abhimenial, como, coloração, pilosidade e a presença ou não da concentração de zonas. A análise da superfície himenial inclui; coloração, formato, bordas e quantidade de poros por $\mathrm{mm}$, além da cor e profundidade dos tubos. Outro fator relevante para identificação é a análise do contexto, verificando, desta forma, tipo, coloração e espessura.

No estudo das características microscópicas, foi considerada a metodologia de Teixeira (8). Os cortes foram realizados com o auxílio de uma lâmina de metal e deixados em torno de um a dois minutos para hidratação com álcool a 70. Em seguida, montados entre lâmina e lamínula em gota de solução aquosa de $\mathrm{KOH}$ a $2 \%$. O reagente de Melzer foi utilizado para o teste das reações amilóides e dextrinóides e quando eram muito hialinas, utilizava-se uma gota de lactofenol ou uma gota de lugol para melhor evidenciá-las. As microestruturas relevantes para o processo de identificação foram observadas, medidas (10 repetições) e ilustradas com o auxílio da câmara clara. As microestruturas analisadas foram: hifas (tipos de hifas e conseqüentemente, definição do sistema hifálico), basidiósporos (forma, tamanho e coloração), tipos de basídios e ausência ou presença de elementos estéreis (cistídios, setas, dendrófises, etc.).

O trabalho de identificação das espécies foi baseado nos trabalhos de: Ryvarden $(9,10)$, Teixeira $(8,11)$, Gugliota e Bononi (3), Bononi (12), Nunez e Ryvarden $(13,14)$ e Index fungorum (http:// indexfungorum.org).

\section{Resultados}

Este trabalho consistiu no primeiro levantamento de espécies de basidiomicetos identificados e descritos para o município de CascavelPR. Foram analisadas dezoito amostras, sendo identificados e descritos 10 táxons classificados em 8 gêneros e 10 espécies.

POLYPORACEAE Corda, Icon. Fug . 3:49. 1939

Basidioma anual à perene apresentando cores neutras como branco a creme, até cores mais intensas, como vermelho, laranja e marrom. Ressupinado, sendo

\section{CHAVE PARA OS GÊNEROS E ESPÉCIES DA CIDADE DE CASCAVEL/PR}

Basidioma séssil a subestipitado

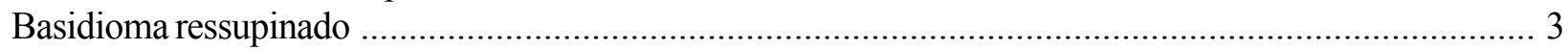

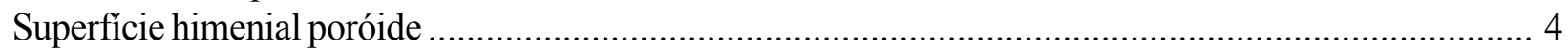

Superfície himenial falsamente lamelar..

Schizophyllum commune

4-6poros por $\mathrm{mm}$, hifas com incrustações.

Schizopora carneo-lutea

7-9 poros por $\mathrm{mm}$, presença de cristais arrosetados. Poria lenis

Basidiósporos de diferentes formas, ápice não truncado

Basidiósporos com ápice truncado

Contexto com bandas vermelho-alaranjadas.

Pycnoporus sanguineus

Contexto sem bandas vermelho-alaranjadas. 7

Cutícula opaca:

esporos $8,75 \times 11,25$ e $5,00 \times 6,25 \mathrm{~mm}$.

Ganoderma australe esporos 8,30-9,96x5,81-7,47 mm. Ganoderma applanatum Cutícula lacada, esporos 10x12,5 e 7,5x8,75 mm. Ganoderma resinaceum Setas presentes no himênio .Phellinus gilvus

Setas ausentes no himênio. 8

Sistema hifálico dímitico, contexto duplex. Coriolopsis polyzona

Sistema hifálico trimítico, contexto homogêneo. Trametes villosa 
totalmente aderido ao substrato a estipitado, com estipes apresentando posições, formatos, colorações e medidas variáveis, a maioria lignícolas, podendo estar solitários, imbricados ou agregados a outros basidiomas. Superfície abhimenial de coloração e pilosidade variáveis, sendo glabra (sem pelos) à totalmente vilosa, apresentando zonas ou não. Superfície himenial geralmente do tipo poróide, porém algumas espécies do tipo lamelar, hidnóide, dedalóide, labirintiforme. Margem podendo ser concolor à superfície abhimenial ou não, como também apresentar ou não zona inferior estéril. Contexto homogêneo a duplex, de coloração e espessura média variável. Sistema hifálico podendo ser mono-di ou trimítico, destacando hifas esqueléticas ramificadas ou não, hifas conectivas e hifas generativas com simples septos ou apresentando ansas, hialinas ou coloridas. Elementos estéreis ausentes ou presentes, como cistídios, setas, dendrófises, etc. Basídios de formas e medidas variáveis. Basidiósporos hialinos a coloridos, geralmente de parede lisa e sempre de parede simples, fina a espessa. As espécies em geral apresentam-se lignícolas, raramente crescendo sobre plantas vivas ou sobre o solo.

Espécie: Poria lenis. (P. Karst.) Sacc., Meddn Soc. Fauna Flora fenn. 14: 82 (1887)

Basiônimo: Physisporus lenis. P. Karst., Rabenhorst's Fungi europ.: no. 3527 (1886)

Basidioma lignícola, anual, ressupinado, cobrindo grande parte da superfície do substrato $(8 \times 3 \mathrm{~cm})$, sendo totalmente aderido a este. Margem, quando presente, concolor à superfície himenial, zona inferior estéril presente até $0,3 \mathrm{~cm}$. Superfície himenial poróide de coloração branca a creme-clara, 6 a 8 poros $/ \mathrm{mm}$ de formato circular, apresentando bordas lisas e inteiras, tubos de coloração creme-clara à marrom, com profundidade variando entre 0,1 a $0,4 \mathrm{~mm}$. Contexto praticamente inexistente, porém, de aspecto delgado e de coloração creme a marrom claro. Sistema hifálico dímitico, com hifas não amilóides e não dextrinóide. Hifas generativas hialinas, fibuladas, ramificadas ou não, parede espessa 1,66-2,49 $\mathrm{mm}$. Hifas esqueléticas ramificadas ou não, com ou sem incrustações, parede espessa 1,66-2,49 mm. Basídios tetraesporados atingindo 8,30 $\mathrm{mm}$. Basidiósporos alantóides, hialinos, de parede delgada 4,15-4,98 $\mathrm{mm} \times 1,66-2,49 \mathrm{~mm}$. Cistídios observados. Cristais arrosetados presentes em abundância, principalmente sobre as paredes das hifas esqueléticas (Figuras 1 a 5-Anexo I).
Espécie: Schizopora carneo-lutea (Rodway \& Cleland), Ceská Mykol. 33(1): 21 (1979)

Basiônimo: Poria carneo-lutea Rodway \& Cleland, Pap. Proc. R. Soc. Tasm.: 18 (1929) [1928]

Basidioma lignícola, anual, ressupinado $(5 \times 4,5 \times 0,1$ $\mathrm{cm}$ ), séssil, totalmente aderido ao substrato. Margem estéril presente, branca, atingindo $0,1 \mathrm{~cm}$ de espessura. Superfície himenial poróide, de coloração creme a creme alaranjada, 6 a 8 poros $/ \mathrm{mm}$, regulares, angulares a circulares, com bordas lisas. Contexto homogêneo, de coloração branca a creme-clara, com espessura atingindo até $0,1 \mathrm{~cm}$, de aspecto frágil. Sistema hifálico dímitico, com hifas não amilóides e não dextrinóides, apresentando ou não incrustações. Hifas generativas com ansas ramificadas ou não, hialinas e de difícil visualização, parede fina, 2,49-3,32 $\mathrm{mm}$. Hifas esqueléticas não ramificadas, hialinas, que reagem com $\mathrm{KOH}-2 \%$, ficando levemente escuras, diâmetro variando entre 2,49-3,32 mm. Basidiósporos elipsóides a su-globosos, (3,32-4,15 x 2,49-3,32 mm), apresentando ou não uma gotícula no citoplasma (Figuras 6 a 8 -Anexo I).

Espécie: Pycnoporus sanguineus. (L.:FR.) Bull. Torrey bot. Club 31(8): 421 (1904).

Basiônimo: Boletus sanguineus L., Sp.pl., Edn 2: 1646 (1763)

Basidioma lignícola, anual, séssil à subestipitado, solitário a lateralmente conato. Píleo dimidiado a flabeliforme, 1,5-6,0 x 1,5-3,5 x 0,1-0,3 cm. Superfície abhimenial de coloração vermelho-alaranjada, tomentosa, concentricamente zonada, ficando glabra com a maturidade e apresentado zonas esbranquiçadas. Margem concolor a superfície abhimenial, direita, aguda, inteira a lobada, zona inferior estéril presente, menor que $0,1 \mathrm{~cm}$. Superfície himenial poróide, concolor a superfície abhimenial, 4 a 6 poros $/ \mathrm{mm}$, regulares, circulares a alongados. Superfície do poro lisa à denteada, tubos concolores com $0,1 \mathrm{a} 1,5 \mathrm{~mm}$ de profundidade. Contexto branco, com zonas concêntricas alaranjadas, 0,1 a $0,8 \mathrm{~mm}$ de espessura. Sistema hifálico trimítico, com hifas generativas hialinas com ansas, parede fina, 1,66-2,49 mm diâm, hifas conectivas ramificadas, hialinas, 1,66 a 2,49 mm diâmetro, hifas esqueléticas hialinas, 2,49 a 3,32 mm diâm, hifas não amilóides e não dextrinóides. Cistídios ausentes. Basídios não observados. Basidiósporos levemente cilíndricos, parede fina e lisa, 3,324,15x2,49 mm (Figuras 9 a 11 - Anexo I). 
Espécie: Trametes villosa (Sw.) Kreisel, Monografias, Ciencias, Univ. Habana, Ser. 4 16: 83 (1971)

Basiônimo: Boletus villosus Sw., Fl. Ind. Occid. 3: 1923 (1806)

Basidioma lignícola, anual, séssil a efluso-reflexo, solitário, imbricado a lateralmente conato. Píleo de formato aplanado, dimidiado a flabeliforme $(1,5-5,0$ x 1,0-4,0x0, $1 \mathrm{~cm})$. Superfície abhimenial de coloração creme-clara a castanha, vilosa e concentricamente zonada. Margem direita a involuta, aguda, inteira a lobada, zona inferior estéril presente, menor que $2 \mathrm{~mm}$. Superfície himenial poróide de coloração creme-clara a tons de amarelo escuro, 1 a 3 poros $/ \mathrm{mm}$, de formato hexagonal e raramente alongado, tubos concolores a superfície himenial e menor que $0,1 \mathrm{~cm}$ de profundidade. Contexto homogêneo, de coloração creme um pouco mais claro quando comparada à superfície himenial atingindo $0,1 \mathrm{~cm}$ de espessura média. Sistema hifálico trimítico, com hifas hialinas de difícil visualização, não amilóides e não dextrinóides, hifas generativas com ansa, de parede fina, $1,66-4,15 \mathrm{~mm}$, hifas ramificadas, 1,66-3,32 $\mathrm{mm}$, hifas esqueléticas arboríformes ou não, de parede espessa, 2,49 a 3,32 mm. Basídios e Cistídios não observados, medas presentes; basidiósporos globosos a subglobosos, hialinos $(4,15-$ $6,64 \times 2,49-3,32 \mathrm{~mm}$ ) (Figuras 12 a 14 -Anexo I).

Espécie: Coriolopsis polyzona (Pers.) Ryvarden, Norw. J1 Bot. 19: 230 (1972).

Basiônimo: Polyporus polyzonus Pers., in Gaud., Voy. Aut. Monde: 170 (1827)

Basidioma lignícola, anual, séssil, solitário a agregado. Píleo flabeliforme $12 \times 7 \times 1 \mathrm{~cm}$. Superfície abhimenial creme-clara a tons de amarelo-escuro em espécies secas, vilosa, porém glabra em espécies envelhecidas, concentricamente zonada. Margem creme à cinza, direita a involuta, aguda, inteira, com pêlos, zona inferior estéril presente até $0,1 \mathrm{~mm}$. Superfície himenial poróide, creme-claro a amarelo-alaranjado, 3 a 4 poros/ $\mathrm{mm}$, circulares, lisos inteiros, tubos concolores à superfície himenial, com profundidade atingindo 0,2 $\mathrm{mm}$. Contexto duplex, de coloração creme-claro, ocráceo, $0,5 \mathrm{~cm}$ de espessura média. Sistema hifálico trimítico, hifas não amilóides e não dextrinóides. Hifas generativas com ansas, hialinas, parede fina, de difícil visualização 2,49-3,32 $\mathrm{mm}$ de diâmetro. Hifas esqueléticas arboríformes ou não, de parede espessa $3,32-5,81 \mathrm{~mm}$ e hifas conectivas de parede fina 2,493,32 mm. Cistídios e outros elementos estéreis ausentes. Basidiósporos cilíndricos, hialinos 2,75-3,75 x 6,25-8,75 mm (Figuras 15 a 18 -Anexo I).

Espécie: Schizophyllum commune Fr. Observ. mycol. (Kjøbenhavn) 1: 103 (1815)

Basiônimo: Agaricus multifidus Batsch, Elenchus fungorum, cont. prim. (Halle): 173 (1786)

Basidioma lignícola, anual, séssil a subestipitado, imbricado a lateralmente conato. Píleo flabeliforme, coriáceo, 1-3x1-2,5x0, 1-0, $2 \mathrm{~cm}$ diâm. Superfície abhimenial acizentada, vilosa, radialmente estriada, concentricamente zonada. Margem concolor à superficie abhimenial, aguda, direita a involuta, lobada. Superfície himenial falsamente lamelar, pois, quando secas, falsas lamelas se enrolam, formando cânulas radiais, de coloração cinza acastanhada. Contexto branco, 0,1 cm de espessura média. Reação com KOH negativa. Sistema hifálico monomítico, hifas generativas com ansas, parede fina a espessas 3,32-5,81 $\mathrm{mm}$. Elementos estéreis não observados. Basidiósporos de formato cilíndricos a alantóides, não amilóides, paredes finas, lisos, hialinos de difícil visualização 4,987,47-1,66-2,49 mm (Figuras 19 e 20 - Anexo I).

\section{GANODERMATACEAE P. Karst. (Rev. Mycol. 3:17), 1881}

Basidioma anual a perene, com coloração variável, amarelo, vermelho, marrom-escuro ou preto. Estipitado a pileado, velutina a glabra. Geralmente ocorre a presença da cutícula, que pode ser lacada e brilhante, de coloração marrom-avermelhado ou opaca de coloração marrom-escuro. Segundo Ryvarden (10), as células da cutícula são diferentes para cada espécie, o que a torna um fator importante para diferenciação das espécies, quando todas as outras características não forem suficientes para a identificação. $O$ fungo Ganoderma australe apresenta a cutícula fina e rala, enquanto o G. resinaceum apresenta a cutícula amilóide em forma paliçada no sentido vertical. A superfície dos poros em geral apresenta a coloração creme, com tamanhos regulares de 4-7/mm, tubos estratificados, contexto geralmente marrom-escuro, podendo também ser de colorações variáveis, duplex ou apresentando diversas bandas ou zonas. Sistema hifálico di-trímitico, hifas generativas com ansas, geralmente hialinas, de difícil visualização em espécimes secos, hifas 
conectivas parede fina, de coloração hialina a amarelo, hifas esqueléticas arboríformes ou não, geralmente parede espessa de coloração amarelo a amarelo-escuro e de diâmetros variáveis. Cistídios ausentes, basídios com 04 esterigmas, basidiósporos ornamentados e truncados, de parede dupla e de tamanhos variáveis.

Espécie: Ganoderma australe (Fr.) Pat., Bull. Soc. mycol. Fr. 5: 65 (1890)

Basiônimo: Polyporus australis Fr., Elench. fung. (Greifswald) 1: 108 (1828)

Basidioma lignícola, perene, séssil, solitário à lateralmente conato. Píleo aplanado a ungulado, $40 \times 20 \times 3 \mathrm{~cm}$. Superfície abhimenial marrom-escuro, apresentando crustas de coloração preta, glabra, concentricamente zonada. Margem creme-clara, direita a involuta, obtusa, lobada, sem pêlos, zona inferior estéril até $0,3 \mathrm{~mm}$. Superficie himenial poróide, de coloração creme a marrom escuro, 4-5 poros $/ \mathrm{mm}$, circulares, lisos inteiros, tubos marrons-avermelhados, 0,1 a $4 \mathrm{~mm}$ de profundidade. Contexto homogêneo, marrom-avermelhado, $0,4 \mathrm{~cm}$ de espessura média. Sistema hifálico dímitico, com hifas não amilóides e não dextrinóides, hifas generativas hialinas, com ansas, parede fina, 1,66-2,49 mm diâm, hifas esqueléticas arboríformes de coloração amarelo a amareloescuro parede espessa 2,49 a 5,81 mm. Basidiósporos elipsóides, truncados, de coloração amarelo à marrom, apresentando endósporo e exósporo separados por uma parede fina, 8,75-11,25 x 5,0-6,25 mm (Figuras 21 a 23 -Anexo I).

OBS.: A espécie Ganoderma australe pode ser facilmente confundida com Ganoderma aplanattum, porém microscopicamente as duas espécies podem ser diferenciadas a partir do tamanho dos basidiosporos, onde Ganoderma australe possui basidiosporos de maior comprimento e menor largura quando comparados aos da espécie Ganoderma aplanattum.

Espécie: Ganoderma applanatum. (Pers.) Pat., Hyménomyc. Eur. (Paris): 143 (1887)

Basiônimo: Boletus applanatus Pers., Observ. mycol. (Lipsiae) 2: 2 (1800) [1799]

Basidioma lignícola, perene, séssil à lateralmente conato. Píleo dimidiado (15-18x3-5x7-8,5 cm). Superfície abhimenial marrom, vilosa, concentricamente zonada. Margem de coloração creme, direita, obtusa $(0,5-0,8$ $\mathrm{cm}$ ), lisa, lobada e zona inferior estéril presente até 0,5 $\mathrm{mm}$. Superfície himenial poróide, de coloração marrom escuro, 5 a 7 poros $/ \mathrm{mm}$, regulares e circulares, tubos concolores a superfície himenial, com 0,1 a 1,1 cm de profundidade. Contexto homogêneo, porém apresentando dois tons de coloração - marrom claro e escuro - espessura média de $0,4 \mathrm{~cm}$. Sistema hifálico dímitico, com hifas não amilóides e não dextrinóides. Hifas generativas hialinas, com ansas, parede fina, 2,49$3,32 \mathrm{~mm}$. Hifas esqueléticas arboríformes de coloração amarelo a marrom, parede espessa 2,49 a 5,81 mm. Basidiosporos ovóides, truncados na região terminal, de parede dupla e coloração marrom, 8,30-9,96x5,81-7,47 mm (Figuras 24 a 26 -Anexo I).

Espécie: Ganoderma resinaceum in Patouillard, Bull. Soc. mycol. Fr. 5: 72 (1890) [1889]

Basidioma lignícola, perene, séssil. Píleo dimidiado, $17 \times 35 \times 11 \mathrm{~cm}$. Superficie abhimenial com a cutícula lacada e brilhante, glabra e separada em sessões que variam a coloração entre marrom-avermelhado, amarelo-escuro e branco. Acutícula lacada expele a resina, que deu a espécie à nominação atual. Margem de coloração creme, direita, obtusa $(0,4-0,7 \mathrm{~cm})$, lisa, inteira, zona inferior estéril presente até $0,2 \mathrm{~mm}$. Superfície himenial poróide, de coloração creme-clara, 3 a 4 poros $/ \mathrm{mm}$, regulares e angulares, tubos concolores a superfície do poro, com 0,1 a 1,2 cm de profundidade. Contexto homogêneo, marrom escuro, espessura média de $4,5 \mathrm{~cm}$, apresentando bandas pretas. Sistema hifálico dímitico, com hifas não amilóides e não dextrinóides. Hifas generativas hialinas, com ansas, parede fina, 2,49-3,75 $\mathrm{mm}$, de difícil visualização em espécimes secos. Hifas esqueléticas arboríformes ou não de coloração amarelo a amareloescuro, parede espessa 2,49 a 6,61 mm. Basídios não observados, elementos estéreis ausentes. Basidiósporos elipsóides, encontrados em abundância no basidioma 7,58,75 x 10-12,5 mm (Figuras 27 a 29-Anexo I).

Phellinus Quél. Elench. Fung. P.172, 1886.

Basidioma perene, ressupinado a pileado, solitário a imbricado. Píleo se apresenta de coloração variável, amarelo, marrom-escuro, vermelho rústico, tomentoso, híspido, glabro. Camadas decorrentes de poros, sendo esses, geralmente, de diâmetros iguais, raramente irregulares e angulares. Contexto de colorações diverso, porém geralmente marrom-ferrugem a amarelo-escuro. Sistema hifálico dímitico, com hifas generativas hialinas sem ansas, apenas simples septadas, hifas esqueléticas amarelas a marrom-ferrugem, geralmente de parede 
dupla. Seta ausente ou presente na trama ou no himênio e hifa setal ausente ou presente no himênio, dentro da margem ou no contexto. Esporos globosos a cilíndricos, hialinos a marrom-ferrugem, parede fina ou dupla, podendo ser dextrinóides ou não. As espécies do gênero se desenvolvem em gimnospermas e angiospermas e também em arvoredos vivos ou mortos.

Espécie: Phellinus gilvus (Schwein.) Pat., Essai Tax. Hyménomyc.: 82 (1900)

Basiônimo: Boletus igniarius L., Sp. Plantarum: 1176 (1753)

Basidioma lignícola, anual à perene, séssil a subestipitado, solitário a imbricado. Píleo de formato dimidiado (2-3×2$5 \times 0,3 \mathrm{~cm}$ ) Superficie abhimenial marrom-claro a marrom escuro, glabra, azonada. Margem concolor à superfície abhimenial, aguda, inteira a lobada, zona inferior estéril até $2 \mathrm{~mm}$. Superfície himenial poróide, marrom-escuro, com a presença de crustas marrom claro a escuro, 8-11 poros $/ \mathrm{mm}$, regulares, circulares, superfície do poro marrom-avermelhado, tubos concolores, atingindo até 1 mm de profundidade. Sistema hifálico dímitico, com hifas generativas sem ansas, apenas simples septadas, 4,15-4,98 $\mathrm{mm}$, e hifas esqueléticas de parede espessa, amarelas a tons de marrom claro, 4,15-4,98 mm. Presença abundante de setas, saindo do himênio, agudas, de parede dupla, de coloração castanha a marrom claro, $18-35$ x 5,81-10,78 $\mathrm{mm}$. Basídios clavados, 5-11 x 5-7 mm. Basidiósporos elipsóides a ovóides, hialinos de difícil visualização, 4,155,81 x 2,49-3,32 mm. (Figuras 30 a 32 -Anexo I).

\section{Discussão e conclusão}

O gênero melhor representado foi Ganoderma, com três táxons e as espécies mais freqüentes foram Trametes villosa e Coriolopsis polyzona. Os fungos basidiomicetos apresentam características que se mantêm em diferentes espécies, principalmente com relação ao basidioma, onde geralmente observase superfície himenial - produtora de esporos - e superfície abhimenial sobrepostas.

A espécie Coriolopsis polyzona pode ser facilmente confundida com Trametes hirsuta, pela apresentação do basidioma e devido à caracterização de apresentar sistema hifálico trimítico, porém o fator determinante que diferencia as duas espécies é o tamanho dos basidiósporos, visto que os da espécie Coriolopsis polyzona são maiores.

As espécies da Família Ganodermataceae foram diferenciadas a partir do tamanho dos basidiósporos e caracterização das células da cutícula, visto que sistema hifálico, verificação dos basídios e outras características não são relevantes para distinção das espécies, devido às semelhanças delas, com relação a esses fatores.

De acordo com a literatura consultada, as espécies identificadas no município de Cascavel-PR, comparadas com espécies já identificadas em outros trabalhos, são todas causadoras de podridão branca, concordando com os dados fornecidos por Ryvarden (9), de que a quantidade de espécies causadoras de podridão branca são maiores nas regiões tropicais. Além disso, são todas lignícolas, com seus basidiomas se desenvolvendo sobre galhos ou troncos em decomposição $(3,15,16,17)$.

Os fungos apresentam uma série de características que os tornam interessantes para aplicação em sistemas de biorremediação (17). Eles são capazes de crescer sob as condições de estresse ambiental que limitam o crescimento bacteriano. Somente a partir de meados da década de 80 foram apresentadas evidências de que o fungo basidiomiceto Phanerochaete chrysosporium tinha a capacidade de degradar e mineralizar compostos xenobióticos como DDT, lindano (1, 2, 3, 4, 5, 6-hexaclorociclohexano) (18), TCDD (2, 3, 7, 8-tetraclorodibenzo- $p$-dioxina), algumas bifenilas policloradas (PCB's) (19). O HCB (hexaclorobenzeno) é encontrado principalmente como resíduo em pesticidas (antrazina, simazina, lindano, pentaclorofenol e outros), resíduo da produção de solventes clorados e da indústria de metais (ferro, cobre e alumínio). O HCB também pode ser gerado pela combustão de compostos clorados, sendo as maiores emissões provenientes da: incineração de resíduos perigosos municipais (tratamento de lixo e esgoto) e médico-hospitalares, produção de cimento, queima de carvão, incineração durante o processamento industrial de ferro, queima de biomassa vegetal e a queima de combustíveis de automóveis.

A degradação da lignina e de poluentes orgânicos por fungos basidiomicetos constitui um processo oxidativo, extracelular e relativamente inespecífico. A degradação consiste em um processo multienzimático resultante da ação coordenada de uma série de enzimas do grupo das oxidoredutases, representadas principalmente por lacases, manganês peroxidases, lignina peroxidases e outras oxidases produtoras de peróxido de hidrogênio e de compostos metabólitos intermediários de baixa massa molecular $(20,21)$. 
Dos táxons identificados apenas dois fungos Ganoderma resinaceum e Pycnoporus sanguineus foram isolados em cultivo asséptico e avaliados quanto à produção das enzimas peroxidases; como a lacase e manganês peroxidase e a capacidade de degradar o corante azul brilhante Remazol (RBBR) (17). Os dois fungos foram capazes de degradar os substratos para as enzimas testadas e descolorir o RBBR, demonstrando desta maneira a aplicabilidade destes fungos nos processos de recuperação de solos contaminados por organoclorados e no tratamento de efluentes da indústria têxtil.

Muitas localidades do município ainda não foram exploradas, devido a isso, esse levantamento não esgota a possibilidade de encontrar outras espécies de poliporáceos.

\section{Agradecimentos}

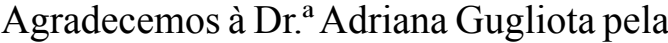
utilização do Herbário do Instituto de Botânica de São Paulo, como também pelo apoio e confirmação das amostras analisadas.

\section{Referências}

1. Alexopoulos CJ, Mims CW, Blackwell M. Introductory mycology. $4^{\text {th }}$. ed. New York: John Wiley \& Sons; 1996.

2. Bononi VLR. Zigomicetos, basidiomicetos e deuteromicetos-noções básicas de taxonomia e aplicações biotecnológicas. São Paulo: Instituto de Botânica; 1999.

3. Gugliota AM, Bononi VLR. Polyporaceae do parque estadual da Ilha do Cardoso. São Paulo: Boletim do Instituto de Botânica. 1999; (2).

4. Santos ERD. Inventário de basidiomicetes lignolíticos em Santa Catarina: guia eletrônico [dissertação]. Santa Catarina: Universidade de Santa Catarina; 2005.

5. Okino LK. Atividade lignolitica de basidiomicetos brasileiros [dissertação]. Rio Claro: Universidade Estadual Paulista; 1996.

6. Valenzuela R, Huerta CP. Los poliporáceos de México V. Algunas espécies dek Norte Del Estado de Queretaro. Polibotânica. 2002; 14:85-122.

7. Fidalgo, O; Bononi, VRL., coord. Técnicas de coleta, preservação e herborização de material botânico. São Paulo: Instituto de Botânica; 1984. 62 p. (Manual n. 4).
8. Teixeira AR. Método para estudos das hifas do basidiocarpo de fungos poliporáceos. São Paulo: Instituto de Botânica; 1995.

9. Ryvarden L. Genera of Polypores. Oslo (Norway). Fungiflora; 1991.v. 5.

10. Ryvarden L. Neotropical Polypores. Oslo (Norway). Fungiflora; 2004. (Pt. 1).

11. Teixeira AR. Chave para identificação dos gêneros de polyporaceae com base na morfologia do basidiocarpo. São Paulo: Boletim do Instituto de Botânica. 1993; 8:1-55.

12. Bononi VLR. Basidiomicetos do Cerrado da Reserva biológica de Moji-Guaçu. São Paulo: Richia; 1984. v. 11, p. 1-25.

13. Núñez M, Ryvarden L. East Asian Polypores. Fungiflora; 2000. v. 1.

14. Núñez M, Ryvarden L. East Asian Polypores. Fungiflora; 2001. v. 2.

15. Bononi VLR. Basidiomicetos xilófilos de la Región Mesopotânica, República Argentina. V. Políporos resupinados. Investigaciones Agrícolas. 1984; 19(1).

16. Valenzuela R, Huerta CP. Los poliporáceos de México V. Algunas espécies dek Norte Del Estado de Queretaro. Polibotânica. 2002; 14:85-122.

17. Machado KMG, Matheus DR, Bononi VLR. Ligninolytic enzymes production and Remazol Brilliant Blue R decolorization by tropical brazilian basidiomycetes fungi. Brazilian Journal of Microbiology. 2005; 36:246-252.

18. Bumpus, JA, Aust, SD. Biodegradation of chlorinated organic compounds by Phanerochaete chrysosporium, a wood-rotting fungus. In: Exner $\mathrm{JH}$. Editores. Solvent Hazardous waste problems: learning from dioxins. Washington DC: American Chemistry Society; 1987. p. 340-349.

19. Bumpus, JA. Biodegradation of polycyclic aromatic hydrocarbons by Phanerochaete chrysoporium. Applied and Environmental Microbiology. 1989; 55:154-158.

20. Mayer, AM, Staples, RC. Laccase: new functions for an old enzyme. Phytochemistry. 2002; 60(6):551-565.

21. Sugiura, M., Hirai, H., Nishida, T. Purification and characterization of a novel lignin peroxidase from white-rot fungus Phanerochate sordida YK-624. FEMS Microbiology Letters. 2003; 224:285-290.

Recebido em/Received in: August 19, 2006 Aceito em/Accepted in: September 20, 2006 


\section{ANEXO}
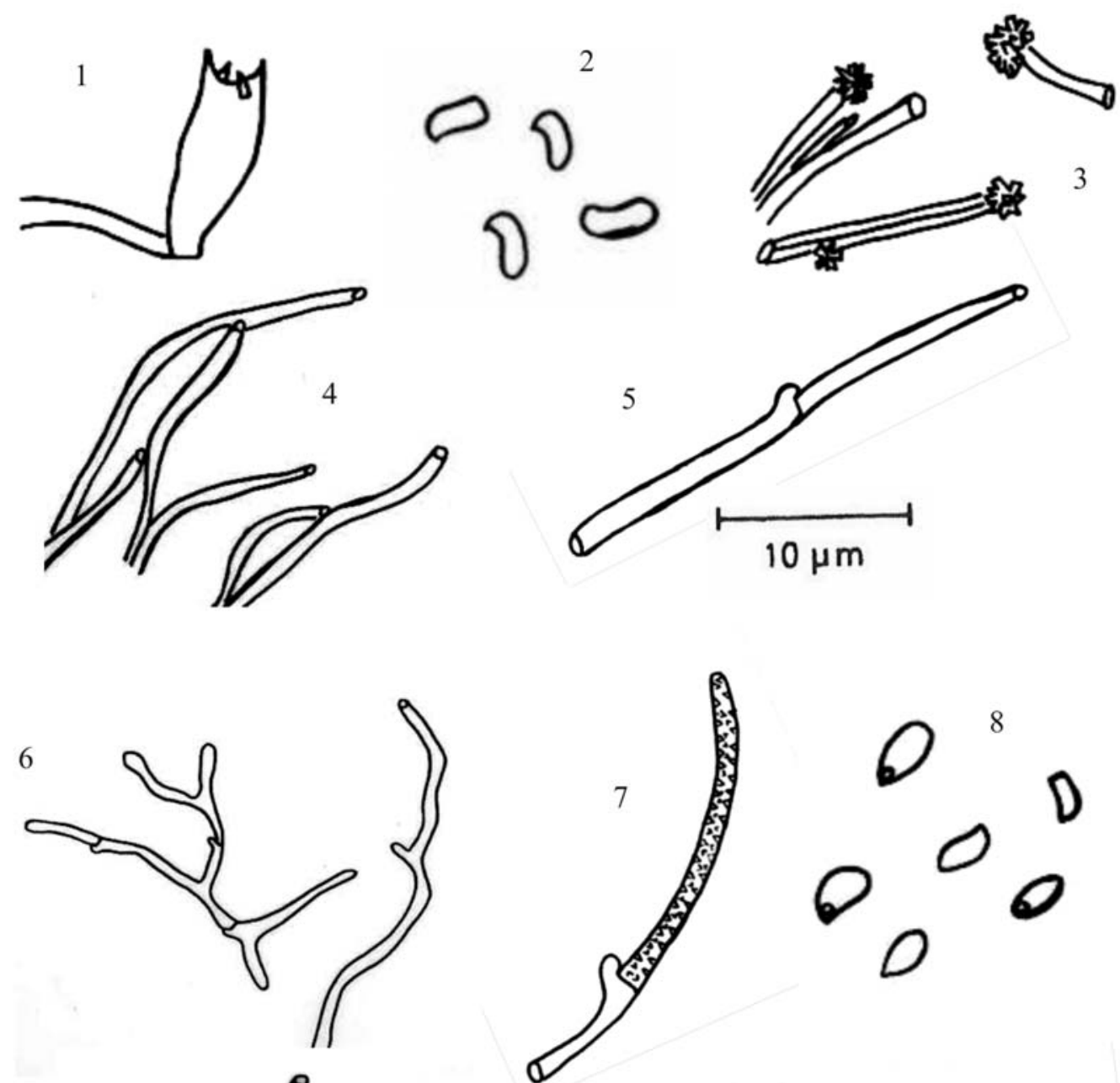

9
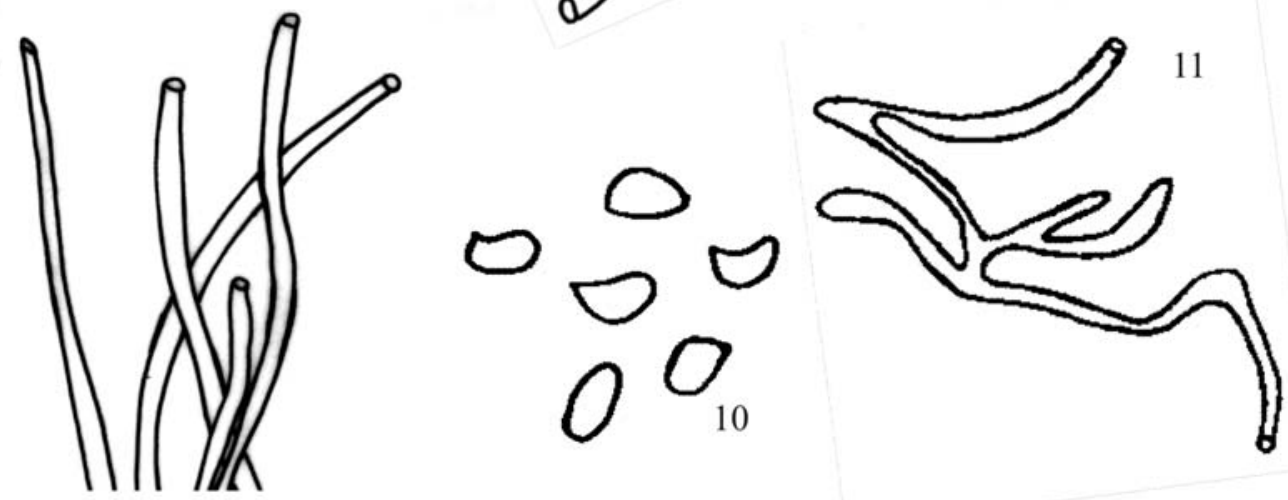

FIGURAS 1-5 - Poria lenis. 1 - basídio; 2 - basidiosporos; 3 - cristais arrosetados; 4 - hifa esquelética; 5 - hifa generativa

FIGURAS 6-8 -Schizopora carneo-lutea. 6 - hifa generativa ramificada e hifa esquelética; 7: hifa generativa com incrustações; 8 - basidiosporos

FIGURAS 9-11- Pycnoporus sanguineus. 9- hifas esqueléticas; 10 - basidiosporos; 11 - hifa conectiva 
12
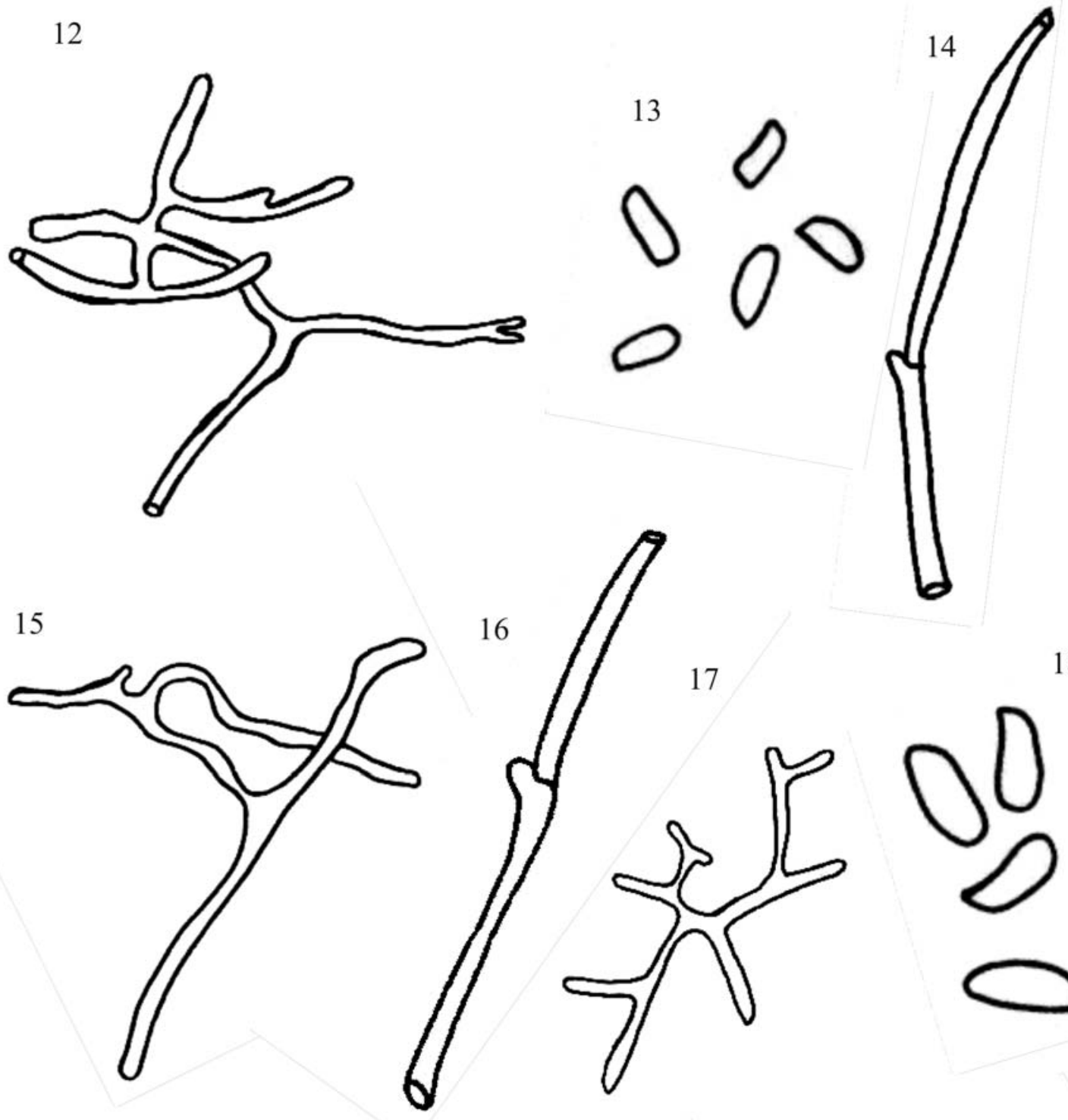

18

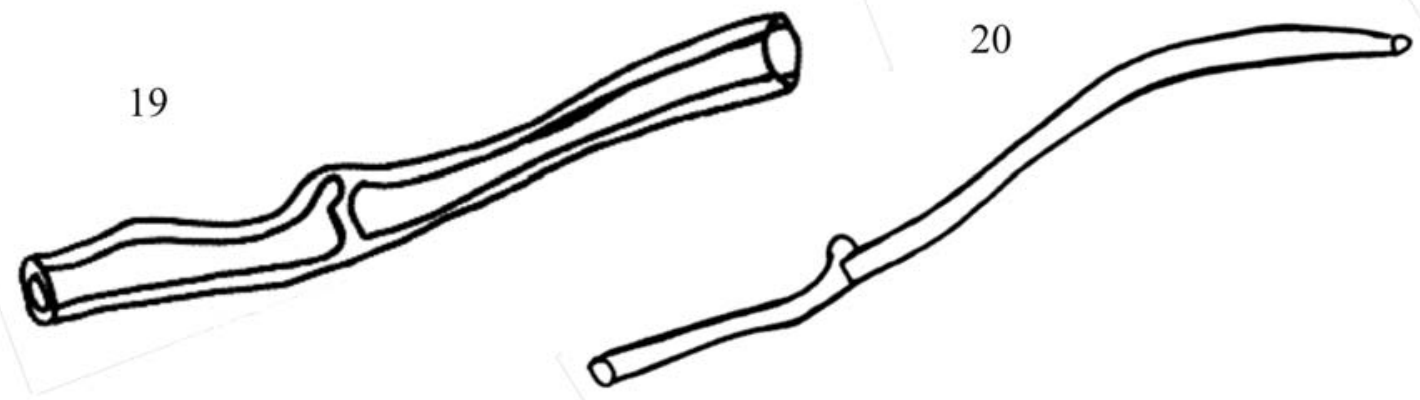

FIGURAS 12-14 - Trametes villosa. 12 - hifa conectiva; 13 - basidiosporos; 14 - hifa generativa FIGURAS 15-18 - Coriolopsis polyzona. 15 - hifa arboriforme; 16 - hifa generativa; 17 - hifa conectiva; 18: basidiosporos

FIGURAS 19-20 - Schizophyllum commune. 19 e 20 - hifas generativas 

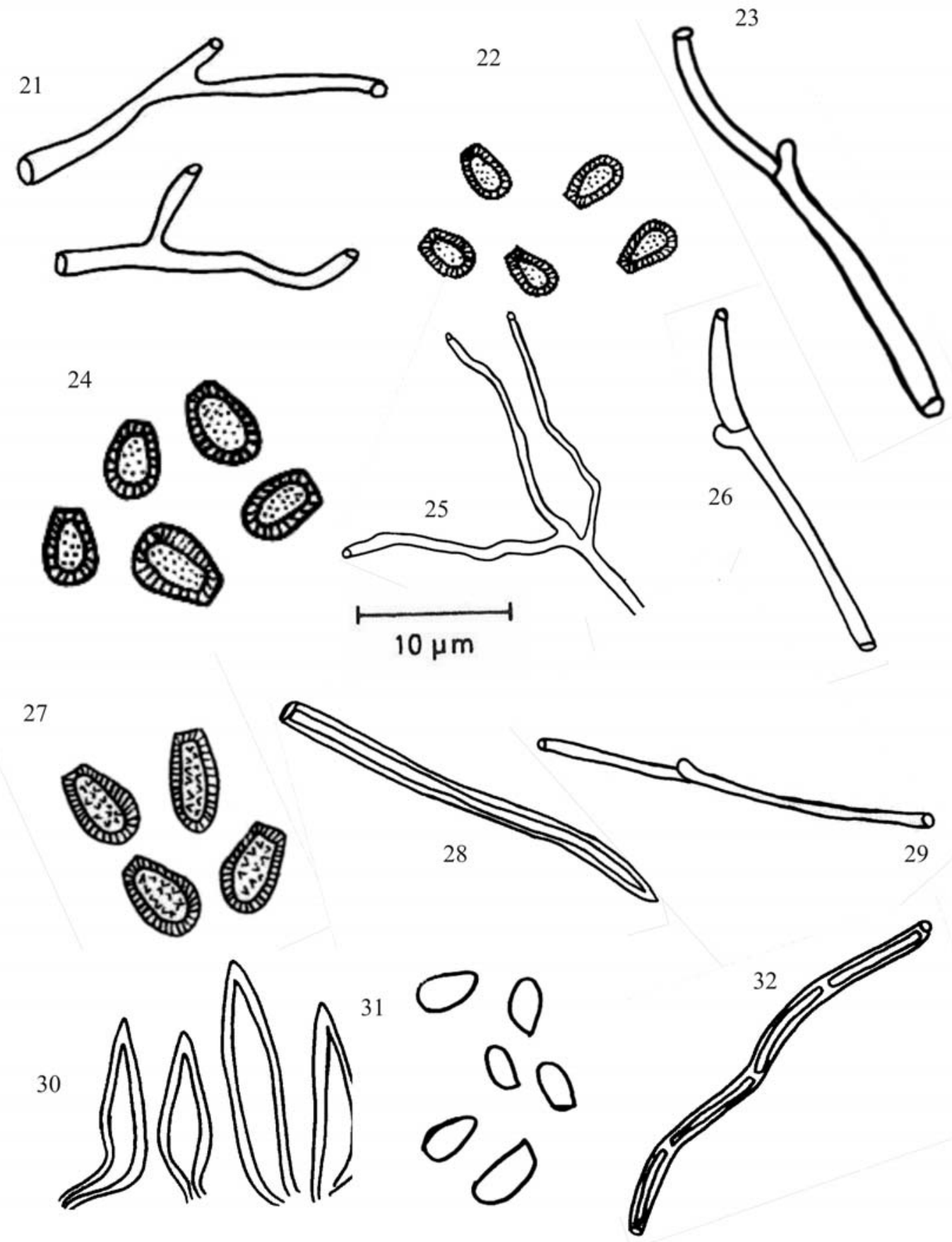

FIGURAS 21-23 - Ganoderma australe. 21: hifas arboriforme; 22: basidiosporos; 23: hifa generativa

FIGURAS 24-26 - Ganoderma applanatum. 24: basidiosporos; 25: hifa arboriforme; 26: hifa generativa

FIGURAS 27-29- Ganoderma resinaceum. 27:basidiosporos; 28: hifa esquelética; 29: hifa generativa

FIGURAS 30-32 - Phellinus gilvus. 30: setas; 31: basidiosporos; 32: hifa generativa 